January 2017

\title{
Exploring the impact of gender inequities on the promotion of cardiovascular health of women in Pakistan
}

Rubina Barolia

Aga Khan University, rubina.barolia@aku.edu

Alexander M. Clark

Clinic Health Academy, University of Alberta, Edmonton, Canada

Gina M. Higginbottom

School of Health Sciences, University of Nottingham, Nottingham, UK.

Follow this and additional works at: https://ecommons.aku.edu/pakistan_fhs_son

Part of the Nursing Midwifery Commons

\section{Recommended Citation}

Barolia, R., Clark, A. M., Higginbottom, G. M. (2017). Exploring the impact of gender inequities on the promotion of cardiovascular health of women in Pakistan. Nursing Inquiry, 24(1), 1-9.

Available at: https://ecommons.aku.edu/pakistan_fhs_son/130 


\title{
Exploring the impact of gender inequities on the promotion of cardiovascular health of women in Pakistan
}

\author{
Rubina Barolia $^{1}$ | Alexander M. Clark ${ }^{2}$ | Gina Higginbottom ${ }^{3}$
}

\author{
${ }^{1}$ School of Nursing and Midwifery, Aga Khan \\ University, Karachi, Pakistan \\ ${ }^{2}$ Faculty of Nursing, Edmonton Clinic Health \\ Academy, University of Alberta, Edmonton, \\ AB, Canada \\ ${ }^{3}$ Mary Seacole Professor of Ethnicity and \\ Community Health, School of Health \\ Sciences, University of Nottingham, \\ Nottingham, UK
}

\section{Correspondence}

Rubina Barolia, School of Nursing and Midwifery, Aga Khan University, Karachi, Pakistan.

Email: Rubina.barolia@aku.edu

\begin{abstract}
Cardiovascular disease exerts an enormous burden on women's health. The intake of a healthy diet may reduce this burden. However, social norms and economic constraints are often factors that restrain women from paying attention to their diet. Underpinned by critical realism, this study explores how gender/sex influences decision-making regarding food consumption among women of low socioeconomic status (SES). The study was carried out at two cardiac facilities in Karachi, Pakistan, on 24 participants (male and female from different ethnic backgrounds), who had received health education. Using an interpretive descriptive approach, the study identified major barriers to a healthy diet: proscribed gender roles and lack of women's autonomy, power, male domination, and abusive behaviours. Cardiovascular risk and disease outcomes for the Pakistani women of low SES are likely to further escalate if individual and structural barriers are not reduced using multifactorial approaches.
\end{abstract}

\section{KEYWORDS}

cardiovascular disease, gender differences, gender inequality, Pakistan, recommended dietary allowances, socioeconomic status
Cardiovascular disease (CVD) is a major cause of death and disability. Since 1984, the prevalence of CVD in low and middle income countries has become greater than that for HIV/AIDS, tuberculosis, cancer, and malaria combined (Shroufi et al., 2013). Additionally, women in the low and middle income countries are more likely to die from CVD than women in high-income countries (Center for Global Health and Economic Development, 2004). This trend can be explained by the wide prevalence of modifiable risk factors, such as smoking, high serum cholesterol, energy-dense diets high in saturated fats and refined carbohydrates, and obesity, combined with a lack of contextually based secondary prevention programmes (Azad \& Nishtar, 2005; Chowdhury et al., 2014).

The intake of a healthy diet is considered the most important modifiable factor that can help prevent the development of CVD. Epidemiological studies have indicated that the intake of a healthy diet reduces CVD and overall mortality (Dehghan et al., 2012). A pooled analysis of participant data from 11 cohort studies found a $26 \%$ reduction in coronary deaths when a $5 \%$ lower energy intake from saturated fatty acids was combined with a higher intake of polyunsaturated fatty acids (Jakobsen et al., 2009; Hooper et al., 2011).

Olinto et al. (2011) noted that scientific literature has shown that dietary patterns are closely related to cultural values, beliefs, and various economic factors. They are also socially constructed with gender roles contributing significantly to dietary choices (Wardle et al., 2004).

Barolia, Clark, and Higginbottom (2013) found that the effect of various factors including gender on the food choices of poor people who have CVD is largely unknown and needs investigation.

Underpinned by critical realism (CR), this is probably the first qualitative study that focuses on understanding how gender influences the food choices of people with low income and CVD in Pakistan. Throughout this study, sex is defined in terms of the biological difference, whereas gender is the person's self-representation as male or female, or how that person responds in social situations is based on individual's gender representation. Moreover, gender is shaped by the environment and by experience (Mosca, Barrett-Connor, \& Kass Wenger, 2011).

\section{1 | CVD PREVALENCE AND PREVENTION IN THE CONTEXT OF PAKISTANI WOMEN}

The people of the South Asian countries, including Pakistan, India, Bangladesh, Sri Lanka and Nepal, are known to have a higher coronary 
disease risk than those living in other parts of the world (Nishtar, 2002; Nishtar \& Voûte, 2007). A population-based, cross-sectional survey of 3,143 adults from randomly selected communities in Karachi showed that one in five middle-aged adults in urban Pakistan may have an underlying coronary artery disease and that women are at greater risk than men (Jafar, Qadri, \& Chaturvedi, 2007).

Modifiable risk factors contribute greatly to this phenomenon. Dennis et al. (2006) studied a mixed population in Karachi, Pakistan, and found that $16 \%$ of the men and $24 \%$ of the women had high cholesterol and that $34 \%$ of the men and $49 \%$ of the women were obese. The gender-related mechanisms creating these sex-based inequities need to be better understood to promote effective means to ameliorate this phenomenon and promote women's health status in Pakistan.

Clinical manifestation of CVD in women appears different from those in men. Generally, CVD symptoms manifest in women at a later age and there are higher rates of silent ischaemia associated with high blood pressure and diabetes (Morin-Martin, Gonzales-Santiago, GilNunez, \& Vivancos-Mora, 2003). Women are not treated in the same manner as men in South Asia and, in particular, in Pakistan (Nishtar \& Voûte, 2007). Hence, secondary prevention of CVD in women is considered less important.

\section{2 | GENDER AND HEALTH: CONTEXTUAL REALITIES IN PAKISTAN}

Pakistan is described as a patriarchal society, in which the status of women is considered as subservient to men (Lee \& Saeed, 2001). In most Pakistani cultures, a woman's position is lower than that of a man's with regard to the distribution of food, health, education and marriage. The allocation of resources in the family is highly dependent on its economic standing and its cultural and religious values. Delavande and Zafar (2013) have pointed out that gender discrimination is also reflected in the women's low literacy rate (29\%, versus $58 \%$ for men, in 2001 ) and excess in mortality, and they are often the recipients of violence. Certain traditions and religious misinterpretations have also reduced women's social status and their access to good nutrition and health-care (Fikree \& Berendes, 2000; MahbubulHaq, 2000; Baig-Ansari, Rahbar, Bhutta, \& Badruddin, 2006). This predominance of gender inequities in social status and health-care access has severely impacted women's health outcomes.

It is important to understand "gender as a social phenomenon" that shapes men's and women's lives and, subsequently, affects their cardiovascular health, among many other things (Bird \& Rieker, 2008). The theory of constrained choices clearly relates gender roles with their impact on positive or negative health behaviour (Reiker \& Bird, 2005). Moreover, social constraints can also differently affect men and women's health. For example, Pakistani wives in many cases cannot seek medical help without their husband's permission; such restrictions result in health consequences.

Empirical research has shown that raising awareness may not be sufficient to change people's high-risk behaviours (Clark, Duncan, Trevoy,
Heath, \& Chan, 2011). Other reasons may exist for the persistence of behaviours such as smoking, poor dietary habits and sedentary lifestyles. This complexity highlights the need for a better understanding of the determinants of behaviour change, including attitudes towards healthy diets that are embedded in gendered and cultural beliefs and practices (Davidson, Trudeau, Van Roosmalen, Stewart, \& Kirkland, 2006; Galdas et al., 2012).

Qualitative inquiry is highly suitable for identifying how beliefs, attitudes and social norms interact in various contexts and how they may serve as facilitators or barriers for Pakistani people to engage in CVD risk-reducing behaviours. The aim of this study was to generate an in-depth understanding of how Pakistani women's food choices and decision-making around food consumption after having CVD are influenced by gender/sex. Two research questions were posed: (1) What are the barriers and facilitators to adapt a healthy diet for Pakistanis of low SES, after CVD diagnosis? (2) How does gender/sex influence Pakistani women of low SES, who have been diagnosed with CVD, in making decision regarding food consumption? The latter is the focus of this study; the findings related to the first research question will be reported separately.

\section{3 | METHOD}

The theory of CR was employed to understand the complex influences of gender and sex on the consumption of healthy diets in the low SES people of Pakistan who have CVD. Bhaskar (1975) proposes that CR helps researcher to gain an understanding of outcomes as they occur. CR stratifies reality and suggests that reality is influenced by various elements, objects, practices and structures. This stratified ontology is central to the $\mathrm{CR}$ philosophy to make sense of a phenomenon that exists within multiple contexts.

Central to CR is the search for broader social structures such as poverty, sex, race and so forth, which exist in society and influence behaviour (Harwood \& Clark, 2011). These structural forces also determine whether individuals recognise or perceive the individual factors that affect their behaviours and contribute to chronic diseases such as CVD. In addition, this theory is best suited for understanding factors about which people are unaware and do not perceive as reasons for their behaviours; however, in reality, they influence their lifestyle. Thus, in this research, CR offered a comprehensive approach for examining the existing gender influences, at the personal and structural levels, that facilitate or hinder dietary changes in women of low SES with CVD.

\subsection{Study design}

The study utilised the qualitative genre of interpretive description (ID) approach. The key axioms of interpretive description are as follows: (a) the lives of the participants are a construct of multiple realities that are "complex, contextual, constructed and ultimately subjective," and (b) the cultural, social and linguistic contexts in which each person lives continually shape and reshape his or her realities (Thorne, 
Con, McGuinness, McPherson, \& Harris, 2004; Thorne, Kirkham, \& O'Flynn-Magee, 2004).

There are two main reasons for using an ID approach with CR. First, CR addresses the complexity of the world in open and natural settings. Similarly, ID addresses the complexity of a phenomenon that can be understood in natural settings (Thorne, 2008). Second, CR emphasises the need to pay particular attention to the existence of diversity in social and cultural systems. Hence, the interpretive aspect of ID allowed the researcher to examine critically the complex decision-making of people, with low SES, regarding their diet (Thorne, Con et al., 2004; Thorne, Kirkham et al., 2004). ID was also used because of its feasibility and practical application. The design strategies of interpretive description do not follow strict prescriptive rules; rather, they guide the researcher to investigate the phenomenon using all aspects of the research (Hunt, 2009; Duggleby, Schroeder, \& Nekolaichuk, 2013). Thus, CR was used as a theoretical lens to view the phenomenon and ID was used to identify relevant strategies to collect and interpret data.

\subsection{Ethical approval}

Review boards at two institutions (Aga Khan University, Karachi, Pakistan, and University of Alberta, Edmonton, Alberta, Canada) granted permission to conduct this study.

\section{3 | Study setting}

The study was conducted in two urban facilities of Karachi, Pakistan, where cardiac patients receive their treatment and other healthcare services at subsidised rates. Karachi is one of the largest cities in the world, with a multiethnic population of 18-20 million people (Barolia et al., 2013). Each group has its own distinct language, place of origin, cultural practices, dietary habits, health beliefs and behaviours. These ethnic variations make the distribution of CVD risk factors complex and multi-faceted (Karachi Metropolitan Corporation, 2016). Both the Centers from where the participants were recruited from provide two to four weeks of comprehensive services, which include education, prescribed exercise, nutritional counselling and behavioural interventions.

\subsection{Sampling and recruitment}

The staff at the cardiac facilities assisted with the recruitment of potential participants. The inclusion criteria for participation included (a) over 30 years of age (the onset of CVD in the South Asian population occurs at a younger age) (Joshi et al., 2007); (b) prior completion of some kind of a cardiac rehabilitation programme or education related to secondary prevention; (c) self-reported income of $\$ 1.25$ (Rs113) or less per day, based on the poverty line defined by Pakistan's economic analysis (Nishtar et al., 2010); (d) ability to speak English or Urdu (the national language of Pakistan); and (e) willingness to talk about and reflect on their experiences with the phenomenon under study. The primary investigator-a native of Pakistan and fluent in English and Urdu-carried out all the consent and data collection procedures.

\section{5 | Data collection}

Semi-structured qualitative interviews were conducted, using an interview schedule, to gather accurate and deep accounts from the participants (Clark, Whelan, Barbour, \& Maclntyre, 2005; Thorne, 2008). The interviews were comprised of open-ended questions, largely aimed at determining the participants' knowledge about healthy diets, who in their household made food purchasing decisions and how these decisions were made, how successful the participants were in changing their diets, and what difficulties were faced in selecting and obtaining healthy food. The participants' perceptions regarding the relative ease or the challenges faced in making dietary changes within the context of limited resources were also an area of interest (Clark et al., 2011). All interviews were audio taped and transcribed also simultaneously with translation into English by the bilingual investigator immediately after the interviews.

\subsection{Data analysis}

Transcribed interviews were compared with the audiotapes to ensure accuracy in translation and to achieve some understanding of the data. Furthermore, the audiotapes were listened to frequently to acquire a deeper understanding of the participants' complex situations. The transcripts were analysed with the aid of ATLAS.ti (Scientific Software Development GmbH, Germany) (Friese, 2012). They were coded and the codes were revised frequently, with similar codes being merged to form preliminary categories. Subsequently, comparable codes and categories were arranged in families, with a graphical network showing the relationships between the codes and categories (Miles, Hubermanand, \& Saldaña, 2013). Next, themes and concepts were formulated to link the data with the broader theoretical formulations.

During data collection and analysis, literature review was also conducted, as a secondary data source, to explore factors that could promote or prevent healthy eating among patients with CVD in the low-income groups. The use of CR and interpretive description produced results that are not only descriptive, but also provide some interpretation and explanation of the participants' dietary practices.

\subsection{Maintaining the rigour of the study}

Thorne (2008) criteria's were used to ensure the rigour of the study. Variant sampling, such as a broad range of age group, males and females, and samples from two different cardiac centres, helped in understanding the phenomenon. The researcher maintained a generous and prolonged engagement with the participants, which resulted in representative credibility. Analytic memos were also prepared to describe the analytic thinking process followed, in order to make sense of the data and to gain an in-depth understanding of it. The preliminary themes and concepts were discussed at length within the research team, during reflective analytical meetings. This assisted in contextualising and articulating specific analytic decisions within the larger picture to reflect analytic logic. 
TABLE 1 Demographic characteristics of the participants $(n=24)$

\begin{tabular}{ll} 
Participants & 24 \\
Male & 12 \\
Female & 12 \\
Age, years (mean/range) & $58.5 / 45-72$ \\
\hline Married/partnered & 23 \\
Employed/unemployed & $20 / 4$ \\
Income & \\
None & 4 \\
5,000 or less & 11 \\
More than 5,000 & 9 \\
Myocardial infarction & 16 \\
Attended cardiac rehabilitation & 17 \\
\hline
\end{tabular}

\section{4 | RESULTS}

Of the 28 eligible participants identified, 24 consented to the interviews. The demographic details of the participants are listed in Table 1.

The results presented in this study focus on the participants' narratives that allowed exploration of individual and structural factors that influence a female CVD patient's dietary decision-making and intake. Themes that reflected the common barriers and facilitators of dietary changes will be discussed elsewhere.

\subsection{Women's understanding of diet}

When asked about their understanding of healthy diets and the importance of diet changes after diagnosis with CVD, most of the participants demonstrated a sound general knowledge regarding the composition of a heart healthy diet. Almost all of them mentioned that traditional diet needs to be avoided as it is salty, spicy and high in fats. However, the participants spoke about the challenges that they faced with regard to complete adoption of a dietary regime, even though they recognised that this change would likely prevent them from further complications. Their reduced capacity to change seemed unrelated to their willingness; it appeared to be linked to their beliefs, customs and gender norms. Four major themes could be identified with respect to challenges related to the consumption of a healthy diet. These are described below:

\subsection{The subservient role of women in the family related to food consumption and making dietary changes}

In most Pakistani cultures, a woman's position is lower than that of a man's in various regards including the distribution of food, health, education and marriage. The majority of women of low SES are most disadvantaged because they have no power to make decisions, even about meal preparation. This is particularly evident for women who are financially dependent on men, as compared to those who are financially independent. This occurs in spite of the fact that most participants, when asked about their food preparation, stated that females are responsible for cooking and household chores.

Most female participants viewed the male in the house as the head or decision-maker, and most male patients who were living in extended families emphasised that they must command, be respected and be able to balance the demands of their parents and wives. When asked about decisions about food preparation at home, the majority of the participants of both the sexes reported that women prepared food for the family. However, some of the females clearly mentioned that they made a conscious effort to prepare food that their men preferred, even when the women or female children in the family were sick or in need of modified diets, such as diet needed after the diagnosis of CVD. Bilquees and Nafisa shed some insights regarding this matter:

\begin{abstract}
A woman has to please her lord [husband]. A woman's only purpose in creation is to serve and please men. If she is sick, she needs to understand who cooks for her family. She has to be modest and not demand certain food by using the excuse of sickness.
\end{abstract}

Honourable women do not demand and expect to have separate food. They must be graceful and avoid disgracing their parents and brothers and the tribe.

Gender norms are also transmitted to the next generation and they are expected to play these roles in the same manner. A few participants who had not received secular education believed that girls should be taught this from early childhood. Among them, Amber stated:

\begin{abstract}
We are women. We cook and clean. That is enough exercise. But now my daughter-in-law does most of the cooking, and she cooks what my son likes. We eat whatever my son wants; he usually likes meat and potatoes. She is only fifteen years old, but she is very active. I am teaching her how to be a good wife.
\end{abstract}

Most of the female participants commented that their choices did not matter and were not respected in society. If female family members have cardiac problems, changing their diet is a difficult matter because the same food is cooked for the whole family, and the men do not easily allow changes in cooking practices. On the other hand, if male family members have cardiac problems, they expect that their wives will understand their needs. A male participant, Asif, affirmed this expectation:

\begin{abstract}
My wife cooks for me. I asked her to attend the dietary lecture and listen carefully to what the doctor was saying about diet... But she needs to understand my taste as well. She and my daughter-in-law cook food that I like, and she also makes it tasty so I can eat it.
\end{abstract}

The fact that families expected value of gender norms and obedience of women was apparent from many of the married participants 
narratives; these women do not make a fuss over the selection of food or complaining about the quality of food. However, where the dietary needs of the male members are concerned, they are expected to take care of them. In this study, a few of the male participants appreciated the women's role regarding looking after their needs. A male participant, Mazhar, commented:

Yes, actually, my wife is my guide; she cares for me more than I can do. If I am on my own I eat a lot of traditional items that I like, but she is very careful about my health. She mostly brings fresh fruit and keeps it for me. She sacrifices her health and gives good care to my old uncle with heart disease. Everyone respects her in the family.

Some of the female participants reported that, after marriage, they are expected to be obedient and to behave in a mature manner. Hence, because of their gender role, and men's lack of support for dietary changes tailored to women's needs, female heart patients are often unable to consume a healthier diet.

\subsection{Food distribution and consumption in the family: A set of power}

When they described the servings of food in terms of quantity and quality, most of the female participants highlighted their unequal share. Women in the low SES of Pakistani society do not have the same rights as the men, but this inequity is considered as normal by women because, from childhood, they are trained to consider males as the powerful members of the family. Male dominance is experienced in all areas of decision-making, particularly in the allocation of household resources. For example, males being served first, at religious and family gatherings, and females eating the leftovers were considered by several women as normal.

Nafisa describing the eating practices at gatherings and celebrations stated:

Actually, it is customary. We prefer to keep good food for our male members. Once they finish, then we females eat, and sometimes there is no food left for us, but we never complain. We all should respect the male members of our family... so our women eat once the males have finished their food. Males do not serve women; it's usually women who serve women.

The study participants also mentioned that adopting preventive measures in regard to food matters can results in severe consequences for them. Some women expressed their fear that negotiating with their husbands over the preparation of less oily and spicy food can lead to domestic violence. Therefore, to maintain family harmony and to prevent arguments, women sacrifice their health. Nazia and her daughters understood the importance of diet in secondary prevention, but they had not been able to act on this knowledge because of the violent behaviour participant's husband:
He fights with me if I do not give him fried meat and beef. We all in the family understand that this food is not good for me or for him. He is an obese person, but he gets angry and shouts, and even hits me when he finds that we have cooked vegetables or legumes, and not prepared the meal according to his wishes. So I have to cook what he likes.

\subsection{Influence of patriarchical social and cultural norms on dietary intake}

The hostile attitude of men towards their wives is not uncommon in families with low income and is not limited to food only. Often, in the patriarchal society in Pakistan, women are held responsible for their husbands' unemployment or low income which oftentimes fails to cover the household expenses. Even if they are willing to seek employment outside the home to share the economic burden, they are usually discouraged, treated lowly and might become victims of violence. One such victim of violence was the wife of Najam, who, instead of gaining permission to work or make dietary changes in the household, was subjected to harsh words and beatings. However, after she died, her husband regretted his abusive behaviour towards his wife and repented. Shedding tears, he said:

I have lost my wife, the most obedient wife. She looked after me so well. She was alive when I had surgery; she really took good care of me. Despite my uncontrolled anger she did not mind.... She wanted to help me with our finances....but I always mistreated her, injured her when she was pregnant. ... I remember I beat her so badly when she asked me to stop eating chaplikabab [fried minced meat cooked with many spices]. She used to take all kinds of anger and bear it without any complaint; she was an angel. [He did not realize her importance and used to beat her.] ... She died; ... She suffered a lot.

Moreover, in Pakistan generally, the marriage of young girls is an important family and social norm; unmarried or divorced women are not respected in society. In fact, unmarried or divorced women, who mostly live with their parents and brothers as per social norms, may experience even more psychological distress than married women. Some female participants brought forth the issue of "marrying off" their daughteran expensive endeavour-which overrode their ability to spend money on purchasing fresh fruits and vegetables. Mothers seemed to be worried more about their daughters' marriage prospects than their disease. Moreover, the tension of their girls' marriage, considering their family's SES, appeared to produce significant psychological distress. One participant, Misbah, described her challenges, related to following dietary prevention practices, in these words:

I have lots of other priorities in my life; my daughters are not married, I have to look for good proposals. I have to save money for their marriages. I do not spend on food, I bring prepared food from the house where I am working so 
my family can eat, I cannot think of my health; right now, this is not my priority.

Marriages of daughters in Pakistan are the most daunting for families having a low income, where the strain on household resources is acute. Hence, parents in these families may be forced into arranging a marriage with a man ten, twenty or even thirty years older than the girl. Among the participants who shared an age difference between spouses, wives were nine or more years younger than their husbands; two women's husbands were twenty and thirty years older than they were. This age discrepancy was expressed by some participants as contributing to family conflict and stress, further reducing their priority to make dietary or other lifestyle changes. Gulshan whose husband is thirty years her senior, stated,

It is because of my husband I got this heart problem. I never enjoyed my life. I'm just living for my children, they are young they need me. I do not want to change my lifestyle. ... it will make no difference. I have to eat what others give and what my children like. I don't think in our society female lives are important.

Apart from worries over the marriage of a daughter or women's distress about overburdening their families, there is added stress when working outside the home becomes necessary for women. Working women have the full responsibility for all household chores in addition to their jobs; women in the low SES do not expect or get any support from their husbands. Salma, mentioning the burden of her work, stated:

I am working here from morning to evening. I just take two hours' break in the afternoon to check on my children and home and come back again in the evening to clean their house. My husband is not earning much. I work here as a house maid and also look after my family, my children, my husband. ... I get so tired. I do not get any help from him [husband]. I cannot focus on eating.

\section{5 | Barriers women face in consuming healthy diets: How and why they overcome them?}

In some cases, the challenges of patriarchy and gendered roles in the family led women to carefully push their boundaries and resist, to some degree, the traditional beliefs and values about how their family consumed food, and about their selfless lifestyles. Some women considered the need for a healthy lifestyle as important more for the sake of their children than themselves. Women with younger children were more inclined to make healthy food choices, and these women tried different strategies, as per their ability. For example, some set aside smaller portions of food having less oil and salt for themselves, then added more ingredients for the rest of the family. Some participants limited their visits to specific restaurants and mosques that serve fatty food. Nazia, whose husband often goes to Afghanistan to work, stated:
When my husband is not here I and my children try to eat $a$ healthy diet. They also support me and eat vegetables with me.... It is difficult when he is in Karachi; he shouts, gets angry if simple food is served; ... when he is not here I can take precautions.

Additionally, because of the patriarchal system that empowers men and early marriages, women fear losing their family, due to their illness. Therefore, women struggle for the safety of their lives and are motivated towards improving their health and strength. Some women expressed that if women in Pakistan are unable to do all of the household chores to take care of their husband and children because of illness, there were greater chances of getting divorced. It was because of these societal norms that females tried to change their diet within whatever limited resources were available to them for maintaining their health, in order to actively do all household activities. As Naheed commented,

Women have to do a lot to please their in laws and husbands, so I used to work day and night to make sure that all my in laws' demands were fulfilled, I even ironed my brothers and sisters-in-law's clothes. I was working twenty-four hours, but after my attack, I took rest for some time, ... But I have to start my work. I eat less salt and try to take a bland diet. I am afraid my in laws may not like it if I get sick again.

In essence, some women tended to change their lifestyle because they realised that without productivity they will be worthless and, hence, discarded.

\section{5 | DISCUSSION}

Using the lens of the theory of critical realism (Bergin, Wells, \& Owen, 2008; Clark, Lissel, \& Davis, 2008; Clark et al., 2011), this study examined major barriers to diet change faced by the women of low SES, at the individual and structural level. It provided useful information on the status of women in the household and revealed obvious gender prejudices. It also revealed that women's low status in the family not only limited their access to nutritious food in general, but also deprived them of healthy food when they had cardiac disease. Bird and Rieker's (2008) theory of constraint explains how women's individual choices, in relation to their diet, are constrained by social factors, family and gender. The framework illustrates that gender interacts with the social, economic and cultural determinants, resulting in different health outcomes for males and females.

The findings also suggest that women's illnesses are not considered serious matters, as compared to those of the men in the family. Other studies conducted in developing countries have also highlighted the cultural bias towards men's health status (Pande, 2003; Patel, 2012; Vlassoff, 2007). The study draws particular attention to the interacting determinants of personal and social factors that reduce the CVD women's capacity to make behavioural changes despite their 
willingness to do so. The underlying notion is that the women in the lower SES in Pakistani society face intense marginalisation, which greatly impedes them from changing their lifestyles and, subsequently, their health status.

The female participants very clearly described their awareness about the types of food required as a healthy diet and their understanding of the importance of changing their health-related behaviours (Chambers, Lobb, Butler, \& Traill, 2008; Clark et al., 2011). However, factors like limited resources, unequal household food distribution and the low status of women in the family, as well as the traditional and patriarchal norms of the society, constrained them from making these changes. Such traditional beliefs were also identified by another qualitative study conducted in an Islamic country, during which women indicated that they were bound to certain family traditions that led to fear and resistance to change (Donnelly et al., 2012).

Consistent with the findings of King, Sanguins, McGregor, and LeBlanc (2007) and Clark et al. (2011), this study found that people of low SES faced a considerable amount of difficulty with regard to meeting their basic needs, such as paying rent and bills, and fulfilling the demands of all members of the household within a scarce income, and this competed with purchasing high-quality food. Moreover, the findings highlighted that marrying young daughters is a higher priority than focussing on one's own health-marriage of girls is an extremely valued norm. Pakistani parents often place more importance on marrying their daughters than on their daughters' education. The participants' testimonials highlighted yet another issue-that negotiating the preparation of less oily, spicy food or asking for some contribution to household duties to make time for exercise can lead to severe consequences, such as losing the husband or domestic violence. This helps explain why some women in the study decided to sacrifice their health to safeguard their family, while others tried to change their eating behaviour within their limited resources in order to maintain harmony in the family.

Nishtar and Voûte (2007) have stressed the need for understanding gender differences that influence CVD preventative efforts, especially in low and middle income countries. These authors emphasise that gender-free, comprehensive, multidisciplinary and integrated approaches are required to prevent CVD in the people of low-income countries. The Millennium Development goals to improve women's health status, along with eradicating hunger and poverty, can only materialise when health policies in developing countries address societal issues that create a low status for women (Azad \& Nishtar, 2005; Grown, Gupta, \& Pande, 2005). This assertion, together with the findings from this study, underlines that health education, using food guides, and various dietary guidelines-regardless of their cultural appropriateness-are not sufficient for behavioural change. Healthcare providers and decision-makers clearly need to implement policies and programmes that facilitate risk reduction strategies within the context of the ethno-cultural norms (Öberg, Jaakkola, Woodward, Peruga, \& Prüss-Ustün, 2011).

The American Heart Association's "Go Red for Women" international awareness campaign encourages women to take charge of their health and urges proactive actions to prevent CVD in women (Go et al., 2012). Without the necessary investment to improve the infrastructures within the education and health sectors and to rectify the inequities, the desired outcome of CVD reduction will not be achieved. For this, strong political commitment is required at the community, national and international levels (Galdas et al., 2012). Women empowerment programmes, such as the Aga Khan Rural Support Program (AKRSP), are beginning to surface, which is encouraging. AKRSP is a private, non-profit organisation, established by the Aga Khan Foundation, which has been successful in improving the access of women to education and health resources, and to economic empowerment opportunities (Bibi \& Ali, 2014; Gul, n.d.). More such programmes should be integrated within the national health agenda and institutionalised within national economic and health policies. Findings of this nature, as highlighted by this study, will help in understanding the multiple barriers and facilitators that can inform decisions about CVD risk reduction in various populations.

\section{6 | STRENGTHS AND LIMITATIONS}

This study was conducted in a specific geographic location, where patients with diverse cultures receive cardiovascular treatment; hence, the findings may not be applicable to the entire low-income population with CVD in Pakistan. Even though interviews were conducted by a native Pakistani, there is a possibility that certain phrases or expressions in Urdu were not given the same meaning in English during translation. This was lessened by contacting the participants to further explain specific terms in some cases. Some women declined to sign the consent forms or complete the interviews in the absence of their husbands; the presence of the husband in these cases may have concealed some of the reality. Credibility and trustworthiness were enhanced by carefully following the applied method of data analysis and through ongoing research team meetings to discuss the emerging themes and interpretations.

\section{7 | CONCLUSIONS AND RECOMMENDATIONS}

Pakistani women's abilities to make dietary and other lifestyle changes towards reducing the risks of CVD prevalence are inextricably linked to their oppression and marginalisation in a male-dominated society. The study can play an important role as it proposes recommendations, targeted at the individual and policy level, that can enable healthcare providers to address cultural and social values during education and treatment efforts, and enable local/regional decisionmakers to drive broader programmatic and policy changes for institutions that provide health and community services for poor people. As a global approach, these health policies can also be integrated with other sectors, such as finance and education, with the goal of reforming social and environmental structures towards equity in health and well-being. 


\section{ACKNOWLEDGEMENTS}

The authors would like to thank International Development Research Centre (IRDC), Ottawa, Canada for funding the study. Many thanks also to the participants in this study and the staff of the hospital who assisted in the recruitment.

\section{REFERENCES}

Azad, N., \& Nishtar, S. (2005). A call for a gender specific approach to address the worldwide cardiovascular burden. Prevention and Control, 1, 223-227.

Baig-Ansari, N., Rahbar, M. H., Bhutta, Z. A., \& Badruddin, S. H. (2006). Child's gender and household food insecurity are associated with stunting among young Pakistani children residing in urban squatter settlements. Food and Nutrition Bulletin, 27, 114-127.

Barolia, R. I., Clark, A. M., \& Higginbottom, G. M. (2013). Protocol for a qualitative study on promoting dietary change and positive food choices for poor people with low income who experience cardiovascular disease in Pakistan. BMJ Open, 3(12), e004176.

Bergin, M., Wells, J. S., \& Owen, S. (2008). Critical realism: A philosophical framework for the study of gender and mental health. Nursing Philosophy, 9(3), 169-179.

Bhaskar, R. (1975). A realist theory of science. Brighton, UK: Harvester.

Bibi, R., \& Ali, A. (2014). An assessment of economic interventions of AKRSP on the lives of women in Chitral. International Journal of Academic Research in Business and Social Sciences, 4(5), 562-571. doi:10.6007/ IJARBSS/v4-i5/882

Bird, C. E., \& Rieker, P. P. (2008). Gender and health: The effects of constrained choices and social policies. New York, NY: Cambridge University Press.

Center for Global Health and Economic Development (2004). A race against time: The challenge of cardiovascular disease in developing economies. New York, NY: The Earth Institute at Columbia University.

Chambers, S., Lobb, A., Butler, L. T., \& Traill, W. B. (2008). The influence of age and gender on food choice: $A$ focus group exploration. International Journal of Consumer Studies, 32, 356-365.

Chowdhury, R., Warnakula, S., Kunutsor, S., Crowe, F., Ward, H. A., Johnson, L., ... \& Di Angelantonio, E. (2014). Association of dietary, circulating, and supplement fatty acids with coronary risk. Annals of Internal Medicine, 160(6), 398-406.

Clark, A. M., Duncan, A. S., Trevoy, J. E., Heath, S., \& Chan, M. (2011). Healthy diet in Canadians of low socioeconomic status with coronary heart disease: Not just a matter of knowledge and choice. Heart and Lung, 40, 156-163.

Clark, A. M., Lissel, S. L., \& Davis, C. (2008). Complex critical realism. Advances in Nursing Science, 31(4), E67-E79.

Clark, A. M., Whelan, H. K., Barbour, R., \& Maclntyre, P. D. (2005). A realist study of the mechanisms of cardiac rehabilitation. Journal of Advanced Nursing, 52, 362-371.

Davidson, K. W., Trudeau, K. J., Van Roosmalen, E., Stewart, M., \& Kirkland, S. (2006). Perspective: Gender as a health determinant and implications for health education. Health Education \& Behavior, 33 731-743.

Dehghan, M., Mente, A., Teo, K. K., Gao, P., Sleight, P., Dagenais, G., ... \& Yusuf, S. (2012). Relationship between healthy diet and risk of cardiovascular disease among patients on drug therapies for secondary prevention: A prospective cohort study of 31546 high-risk individuals from 40 countries. Circulation, 126(23), 2705-2712.

Delavande, A., \& Zafar, B. (2013). Gender discrimination and social identity: Experimental evidence from urban Pakistan. New York, NY: Federal Reserve Bank of New York. Retrieved from https://www.econstor.eu/ dspace/handle/10419/93644

Dennis, B., Aziz, K., She, L., Faruqui, A. M., Davis, C. E., Manolio, T. A., ... \& Aziz, S. (2006). High rates of obesity and cardiovascular disease risk factors in lower middle class community in Pakistan: The Metroville Health Study. Journal of the Pakistan Medical Association, 56(6), 267-272.

Donnelly, T. T., Al Suwaidi, J., Al Enazi, N. R., Idris, Z., Albulushi, A. M., Yassin, K., ... \& Hassan, A. H. (2012). Qatari women living with cardiovascular diseases: Challenges and opportunities to engage in healthy lifestyles. Health Care for Women International, 33, 1114-1134.

Duggleby, W., Schroeder, D., \& Nekolaichuk, C. (2013). Hope and connection: The experience of family caregivers of persons with dementia living in a long term care facility. BMC Geriatrics, 13(1), 112.

Fikree, F. F., Khan, A., Kadir, M. M., Sajan, F., \& Rahbar, M. H. (2001). What influences contraceptives use among young women in urban squatter settlements of Karachi, Pakistan? International Family Planning Perspectives, 27(3), 130-136.

Friese, S. (2012). Qualitative data analysis with ATLAS.ti. London: Sage.

Galdas, P. M., Oliffe, J. L., Wong, S. T., Ratner, P. A., Johnson, J. L., \& Kelly, M. T. (2012). Canadian Punjabi Sikh men's experiences of lifestyle changes following myocardial infarction: Cultural connections. Ethnicity \& Health, 17, 253-266.

Go, A., Mozaffarian, D., Roger, V., Benjamin, E., Berry, J., Borden, W., ... \& American Heart Association Statistics Committee and Stroke Statistics Subcommittee. (2012). Heart disease and stroke statistics - 2013 update: A report from the American Heart Association. Circulation, 127(1), e6-e245.

Grown, C., Gupta, G., \& Pande, R. (2005). Taking action to improve women's health through gender equality and women's empowerment. The Lancet, 365(9458), 541-543.

Gul, R. (n.d). Impact of Aga Khan Rural Support Program's gender strategy on rural women in District Chitral. Wikieducator.net: 1-9. Retrieved from http://wikieducator.net/images/2/27/PID_720.pdf.

Harwood, L., \& Clark, A. M. (2011). Understanding health decisions using critical realism: Home-dialysis decision-making during chronic kidney disease. Nursing Inquiry, 19(1), 29-38.

Hooper, L., Summerbell, C. D., Thompson, R., Sills, D., Roberts, F. G., Moore, H., \& Davey Smith, G. (2011). Reduced or modified dietary fat for preventing cardiovascular disease. Cochrane Database of Systematic Reviews, 6(7), CD002137. doi:10.1002/14651858.cd002137.pub2

Hunt, M. R. (2009). Strengths and challenges in the use of interpretive description: Reflections arising from a study of the moral experience of health professionals in Humanitarian Work. Qualitative Health Research, 19(9), 1284-1292.

Jafar, T. H., Qadri, Z., \& Chaturvedi, N. (2007). Coronary artery disease epidemic in Pakistan: More electrocardiographic evidence of ischaemia in women than in men. Heart, 94, 408-413.

Jakobsen, M. U., O'Reilly, E. J., Heitmann, B. L., Pereira, M. A., Balter, K., Fraser, G. E., ... \& Ascherio, A. (2009). Major types of dietary fat and risk of coronary heart disease: A pooled analysis of 11 cohort studies. American Journal of Clinical Nutrition, 89(5), 1425-1432.

Joshi, P., Islam, S., Pais, P., Reddy, S., Dorairaj, P., Kazmi, K., ... \& Yusuf, S. (2007). Risk factors for early myocardial infarction in South Asians compared with individuals in other countries. JAMA, 297(3), 286.

Karachi Metropolitan Corporation. (2016). Welcome to Karachi City. Retrieved from http://karachicity.gov.pk.

King, K. M., Sanguins, J., McGregor, L., \& LeBlanc, P. (2007). First Nations people's challenge in managing coronary artery disease risk. Qualitative Health Research, 17(8), 1074-1087.

Lee, M. B., \& Saeed, I. (2001). Oppression and horizontal violence: The case of nurses in Pakistan. Nursing Forum, 36(1), 15-24.

Mahbub ul Haq Human Development Centre. (2000). Human development in South Asia: The gender question. Oxford: Oxford University Press.

Miles, M. B., Hubermanand, A. M., \& Saldaña, J. (2013). Qualitative data analysis: A methods sourcebook, 3rd ed.. Los Angeles/London/New Delhi: Sage.

Morin-Martin, M., Gonzales-Santiago, R., Gil-Nunez, A. C., \& Vivancos-Mora, J. (2003). Women and strokes: Hospital epidemiology in Spain. Review of Neurology, 37, 701-705. 
Mosca, L., Barrett-Connor, E., \& Kass Wenger, N. (2011). Sex/gender differences in cardiovascular disease prevention: What a difference a decade makes. Circulation, 124(19), 2145-2154.

Nishtar, S. (2002). Prevention of coronary heart disease in south Asia. The Lancet, 360(9338), 1015-1018.

Nishtar, S., Khalid, F., Ikram, A., Kazi, A., Mirza, Y. A., Khattak, I. H., ... \& Badsha, T. (2010). Protecting the poor against health impoverishment in Pakistan: Proof of concept of the potential within innovative Web and mobile phone technologies. World Health Report Background $\mathrm{Pa}$ per \#55. Geneva: World Health Organization.

Nishtar, S., \& Voûte, J. (2007). Women and heart disease: Time for change. Nature Clinical Practice Cardiovascular Medicine, 4, 231.

Öberg, M., Jaakkola, M. S., Woodward, A., Peruga, A., \& Prüss-Ustün, A. (2011). Worldwide burden of disease from exposure to second-hand smoke: A retrospective analysis of data from 192 countries. The Lancet, 377(9760), 139-146.

Olinto, M. T., Gigante, D. P., Horta, B., Silveira, V., Oliveira, I., \& Willett, W. (2011). Major dietary patterns and cardiovascular risk factors among young Brazilian adults. European Journal of Nutrition, 51, 281-291.

Pande, R. (2003). Selective gender differences in childhood nutrition and immunization in rural India: The role of siblings. Demography, 40, 395-418.

Patel, R. C. (2012). Food sovereignty: Power, gender, and the right to food. PLoS Medicine, 9(6), e1001223.

Rieker, P. P., \& Bird, C. E. (2005). Rethinking gender differences in health: Why we need to integrate social and biological perspectives. Journals of Gerontology (Series B), 60B(2), 40-47.
Shroufi, A., Chowdhury, R., Anchala, R., Stevens, S., Blanco, P., Han, T., ... \& Franco, O. H. (2013). Cost effective interventions for the prevention of cardiovascular disease in low and middle income countries: A systematic review. BMC Public Health, 13(1), 285.

Thorne, S. (2008). Interpretive description. Walnut Creek, CA: Left Coast Press.

Thorne, S., Con, A., McGuinness, L., McPherson, G., \& Harris, S. R. (2004). Health care communication issues in multiple sclerosis: An interpretive description. Qualitative Health Research, 14(1), 5-22.

Thorne, S., Kirkham, S. R., \& O'Flynn-Magee, K. (2004). The analytic challenge in interpretive description. International Journal of Qualitative Methods, 3(1), 1-21.

Vlassoff, C. (2007). Gender differences in determinants and consequences of health and illness. Journal of Health, Population, and Nutrition, 25(1), 47-61.

Wardle, J., Haase, A. M., Steptoe, A., Nillapun, M., Jonwutiwes, K., \& Bellisie, F. (2004). Gender differences in food choice: The contribution of health beliefs and dieting. Annals of Behavioral Medicine, 27, 107-116.

How to cite this article: Barolia, R., Clark, A.M. and Higginbottom, G. (2016), Exploring the impact of gender inequities on the promotion of cardiovascular health of women in Pakistan. Nursing Inquiry, 00: 1-9. doi: 10.1111/nin.12148. 